\title{
Mathematical modelling of a flow-injection system with a membrane separation module
}

\author{
Spas D Kolev ${ }^{1}$ and Willem $E$ van der Linden \\ Laboratory for Chemucal Analysus, Department of Chemucal Technology, University of Twente, PO Box 217, \\ NL-7500 AE Enschede (Netherlands)
}

(Received 24th February 1992)

\begin{abstract}
A mathematical model for a flow-injection system with a membrane separation module based on the axially dispersed plug flow model was developed It takes into account the geometncal dimensions and dispersion properties of the man sections of the manifold, the mass transfer in the channels of the separation module and the characteristics of the membrane (thickness and diffusion coefficient within it) The model was solved analytically in the Laplace domain The inverse transformation was found to give satısfactory results for reactor Peclet numbers less than 120 Otherwise a numerical solution based on the implicit alternating-direction finite difference method was preferred The adequacy of the model was confirmed experimentally on a flow-injection manifold with a parallel-plate dialysis module The unknown flow and membrane parameters were determined by curve fittung The membrane parameters were determined also by steady-state measurements Farly good agreement between the dynamic and steady-state results and with results given in the literature was observed, which, together with other experimental results, supported the validity of the model and showed that it can be used successfully for the mathematical description and optımization of flow-injection systems with membrane separation modules In this connection, the influence of the reactor parameters and the sample volume on the performance of such a system were investigated and conclusions for improving its sensitivity and sample throughput were drawn Other possible applications of the model are in membrane technology for characterizing of various membranes and in process engineenng for investigating the mass transfer in different dialysers
\end{abstract}

Keywords Flow-ınjection, Optımızation methods, Dialysis separatıon, Mathematical modellıng, Membrane permeability

Flow-injection manifolds with modules for dialysis or gas diffusion have been shown to be very useful in dealing with samples containing macromolecules, particles or cells by separating them from the analyte prior to detection [1-4] In this way, malfunctioning of the detector due to processes associated with the species mentioned above (e g, clogging, light scattering) can be ef-

Correspondence to S D Kolev, Laboratory for Chemical Analysis, Department of Chemical Technology, University of Twente, P O Box 217, NL-7500 AE Enschede (Netherlands)

1 Permanent address Faculty of Chemistry, University of Sofia, Anton Ivanov Ave 1, BG-1126 Sofia (Bulgana) fectively prevented, thus securing accurate and reproducible results This makes the flow-injection dialysis systems very advantageous in various fields (e $\mathrm{g}$, clınıcal analysıs $[3,4]$ ) where, in addıtion to the accuracy and reproducibility of the analysis, a high sample throughput with minimum consumption of reagents is of crucial importance

The mass-transfer process in the dialysis module of a flow-injection system is determined to a considerable extent by the properties of the membrane (1 e, its thickness and diffusivity) This allows experimental characterization of semi-permeable membranes using such systems [5] 
For a better understanding of the processes taking place in a flow-injection manifold with a dialysis module, an adequate mathematical model is necessary On the one hand, it will give poss1bilities for deriving guidelınes for optimization of both the design and the operation of these man1folds, thus avoiding the costly and time-consuming "trial and error" approach On the other hand, it will allow the separation of the contribution of the membrane to the overall mass transfer from that of the flow pattern in both channels of the dialysis module This is necessary when the flow system is used for membrane characterization or for investigating the mass transfer in the channels

Theoretical investigations of the mass-transfer process in dialysers based on fundamental physical laws (e g, the Navier-Stokes equations and Fick's second law) have been limited mainly to the case of fully developed laminar flow in both channels and steady-state mass transfer The reason for this situation is that industrial mass exchangers and haemodialysers used as artificial kıdneys work under such conditions and the overall effect of the transient periods (e g, start-up, shut-down, power surge and pump fallure) is usually negligible However, in flow-injection manifolds with dialysis separation, the transient mass transfer becomes the process governing the performance The exact mathematical description must include the time dependence of the masstransfer process, which greatly complicates the corresponding mathematical solution

Bernhardsson et al [6] used the approach mentioned above for the modelling of a flow-injection manifold assumed to consist of a dialysis module only and to operate under steady-state conditions The latter assumption does not permit the calculation of the concentration profiles at the outlets of both channels under flow-injection conditions because they are the result of transient mass transfer The model was successfully used for determining the membrane permeability [6,7]

The overall performance of a flow-injection manifold with a dialysis module depends on the processes takıng place in all the separate sections (e g, injection valve, reactor) Because of the complexity of the real hydrodynamic regime in the different sections, the development of a general mathematical model based on fundamental physical laws is exceedingly difficult and in most instances virtually impossible

A possible approach for predicting the outlet concentration profiles of a given dialysis module is to find its impulse-response function under certain experimental conditions This can be performed by deconvolution of the concentration profiles obtained under identical experimental conditions in a flow-injection manifold with and without the dialysis module $[8,9]$ However, it is difficult to relate the impulse-response function obtained in this way to the parameters that most affect the bchaviour of the dialyser and to extend the results to other sets of parameters values

The approach used in chemical engineering for the mathematical description of such complex flow systems is based on the application of the so-called hydraulıc models (e g, tanks-ın-series, dispersion, combined and empirical models) $[10,11]$ In the modelling of flow-injection manıfolds, the thanks-in-series and the dispersion models have been most frequently used $[1,2]$ For the mathematical description of flow-injection systems with membrane separation, the tanks-inseries model without back-mixing and with equal size of the tanks was used [12] and gave satisfactory qualitative agreement with the experimental results However, most of the flow-through sections in a flow-injection manifold are tubular and for that reason the dispersion models appear to be closer to the real physical situation Among them, the axially dispersed plug flow model [10] deserves special attention because it is simpler from a mathematical point of view and it has been already successfully utllized in the modelling of single-line flow-injection systems [13-17] The flow pattern prevalling in these systems is laminar and another advantage offered by the axially dispersed plug flow model is the possibility of calculating the laminar Peclet number in both their tubular $[18,19]$ and parallel-plate [20] sections For parallel-plate dialysis modules, a theoretical relationship for determining the laminar flow mass-transfer coefficients in both channels has also been derived [21] 


\section{TABLE 1}

Symbols and definitıons a

$a$

A

$B$

$c$

Half of a channel height or radius of a tubular section (m)

Integrational constants (Appendix A)

Integrational constants (Appendix A)

Concentration $\left(\mathrm{mol} \mathrm{m}^{-3}\right)$

Initial tracer concentration $\left(\mathrm{mol} \mathrm{m}^{-3}\right)$

$=c_{0} V_{\mathrm{inj}} / V_{\mathrm{t}}$ Average concentration $\left(\mathrm{mol} \mathrm{m}^{-3}\right)$

$=c / c_{\text {av }}$ (under flow-injection conditions) or $=c / c_{0}$ (under steady-conditıons) Dimensionless concentration

Laplace transform of $C$

Molecular diffusion coefficient $\left(\mathrm{m}^{2} \mathrm{~s}^{-1}\right)$

Axıal dispersion coefficient $\left(\mathrm{m}^{2} \mathrm{~s}^{-1}\right)$

Peak broadenıng (s)

$=e v_{\mathrm{D}} / V_{\mathrm{t}}$ Dimensionless peak broadening

Coefficient defined in Appendix A

$=c_{\mathrm{m}} / c_{\mathrm{Dm}}$ or $c_{\mathrm{m}} / c_{\mathrm{Am}}$ Distribution coefficients

Coefficient defined in Appendix A

Coefficient defined in Appendix A

$=k a_{\mathrm{D}} / D_{\mathrm{m}}$ Dimensionless group

Mass-transfer coefficient (m s ${ }^{-1}$ )

$=k V_{\mathrm{t}} / 2 a v_{\mathrm{D}}$ Dimensionless mass-transfer coefficient

Number of $\theta$ subintervals (Appendix B)

$=x_{2}$ Characteristic length (m)

Coefficients defined in Appendix A

Number of $Y$ subintervals (Appendix B)

Number of $X$ subintervals (Appendix B)

Laplace complex variable

$=\bar{u} L / D_{\mathrm{L}} \quad$ Peclet number

$=a_{\mathrm{D}}^{2} v_{\mathrm{D}} / D_{\mathrm{m}} V_{\mathrm{t}}$ Dimensionless group

Coefficients defined in Appendix A

Coefficient defined in Appendix A

Integrational constants (Appendix A)

Cross-sectional area of a flow section $\left(\mathrm{m}^{2}\right)$

Coefficient defined in Appendix A

Time (s)

Mean linear flow-rate $\left(\mathrm{m} \mathrm{s}^{-1}\right)$

Volumetric flow-rate $\left(\mathrm{m}^{3} \mathrm{~s}^{-1}\right)$

$=s L$ Volume $\left(\mathrm{m}^{3}\right)$

Injected volume of tracer $\left(\mathrm{m}^{3}\right)$

$=\pi a_{\mathrm{r}}^{2} x_{1}+2 a_{\mathrm{D}} w\left(x_{2}-x_{1}\right)$ Characteristic volume

Width of the channels of the membrane separation module (m)

Axıal distance (m)

$=x / L$ Dimensionless axial distance

Transverse distance $(\mathrm{m})$

$=y / a_{\mathrm{D}}$ Dimensionless transverse distance

Roots of Eqn A20

\section{Greek letters}

$\alpha \quad$ Coefficient defined in Appendix A

$\beta \quad$ The only negative root of Eqn C3

$\gamma \quad=V_{t} / V$ Coefficients

$\delta \quad$ Half-width of the membrane (m)

$\Delta \quad=\delta / a_{\mathrm{D}}$ Dimensionless half-width of the membrane

$\Delta X \quad X$ increment (Appendix B)

$\Delta Y \quad Y$ increment (Appendix B) 
TABLE 1 (continued)

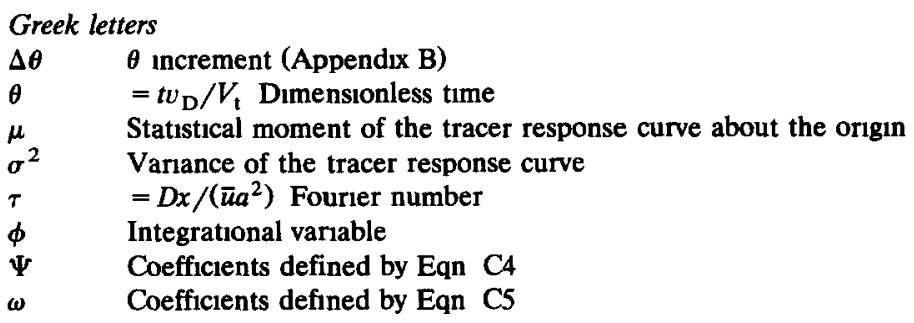

a Subscripts $f, 1, r$ and a refer to the fore-section, the injection section, the reactor and the after-section, respectively, D, A and $m$ refer to the donor channel, the acceptor channel and the membrane, respectively, Dm and Am refer to the donor stream/membrane and the acceptor stream/membrane interfaces, respectively, max refers to maximum concentration Superscript * refers to the acceptor line

The aim of this paper is to outline a mathematical model of a flow-injection system with a membrane separation module based on the axially dispersed plug flow model, its experimental verification and the formulation of guidelines for improving its performance

Among the various types of dialysers used in industry and medical practice and for analytical purposes ( $1 \mathrm{e}$, parallel-plate, tubular and spiralplate dıalysers), parallel-plate dialysers have been used most frequently in flow-injection manifolds For this reason, the experimental verification of the model was performed on a flow-injection manifold with a parallel-plate dialysis module

DEVELOPMENT AND SOLUTION OF THE MATHEMATICAL MODEL

\section{Description of the model}

A flow-injection manifold with a membrane separation module which may have arbitrary geometry can be presented schematically as consisting of one donor and one acceptor line ( $\mathrm{F}_{1} \mathrm{~g} \mathrm{1}$ ) The donor line includes the following flowthrough sections connected in series the foresection, which connects the injection device with the reservoir of the carrier solution, the injection section (usually an injection valve), the reactor, which could be a straight, colled, packed-bed, single-bead string or knitted tube, the donor channel inside the membrane separation module, and the after-section, which is the section of the flow system leading to waste Simularly, the acceptor line consists of fore-section, acceptor channel and after-section The measuring cell is assumed to be downstream of the acceptor channel Its volume is usually negligible in comparison with the volume of the reactor and the two channels inside the membrane separation module. For this reason, it is not included as a separate element in the schematic representation of the acceptor line The additional assumptions on which the model Is built are the following (1) the dispersion of the analyte in all sections of the manifold can be described by the axially dispersed plug flow model (Eqn 1), (11) the fore- and after-sections are tubular and infinitely long, so that the so-called "end effects" [22] can be neglected and Taylor's theory $[18,19]$ can be used for calculating their Peclet

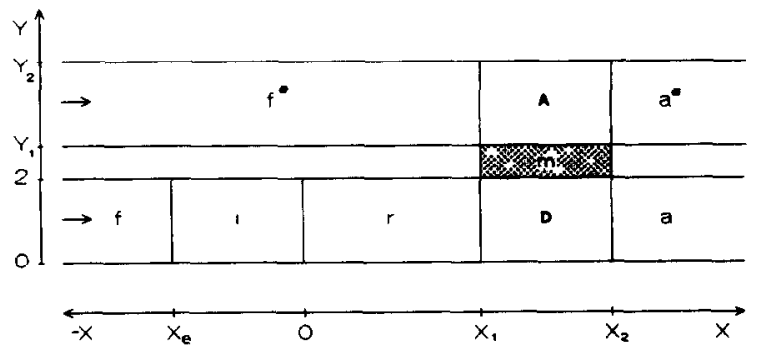

Fig 1 Scheme of flow-injection manifold with membrane separation module $f, 1, r$ and a refer to the fore-section, the injection section, the reactor and the after-section, respectively, $\mathbf{D}$ and $\mathbf{A}$ refer to the donor and the acceptor channels, respectively, and * refers to the acceptor line, $Y_{1}=2(1+\Delta)$, $Y_{2}=2\left(1+\Delta+a_{A} / a_{D}\right)$ 
numbers (Eqn 2), and the mass transport within the membrane is caused by transverse Fickian diffusion only (All symbols are defined in Table 1)

$\frac{\partial C}{\partial \theta}=\frac{1}{P} \frac{\partial^{2} C}{\partial X^{2}}-\frac{\partial C}{\partial X}$

$P=48 D L /\left(\bar{u} a^{2}\right)$

The flow system shown in Fig 1 can be described by the following set of partial differential equations in dimensionless quantities and var1ables similar to Eqn 1

For the donor line

$\frac{\partial C_{\mathrm{f}}}{\partial \theta}+\gamma_{\mathrm{f}} \frac{\partial C_{\mathrm{f}}}{\partial X}-\frac{\gamma_{\mathrm{f}}}{P_{\mathrm{f}}} \frac{\partial^{2} C_{\mathrm{f}}}{\partial X^{2}}=0 \quad X \leqslant X_{\mathrm{e}}$

$\frac{\partial C_{1}}{\partial \theta}+\gamma_{1} \frac{\partial C_{1}}{\partial X}-\frac{\gamma_{1}}{P_{1}} \frac{\partial^{2} C_{1}}{\partial X^{2}}=0 \quad X_{\mathrm{e}} \leqslant X \leqslant 0$

$\frac{\partial C_{\mathrm{r}}}{\partial \theta}+\gamma_{\mathrm{r}} \frac{\partial C_{\mathrm{r}}}{\partial X}-\frac{\gamma_{\mathrm{r}}}{P_{\mathrm{r}}} \frac{\partial^{2} C_{\mathrm{r}}}{\partial X^{2}}=0 \quad 0 \leqslant X \leqslant X_{1}$

$\frac{\partial C_{\mathrm{D}}}{\partial \theta}+\gamma_{\mathrm{D}} \frac{\partial C_{\mathrm{D}}}{\partial X}-\frac{\gamma_{\mathrm{D}}}{P_{\mathrm{D}}} \frac{\partial^{2} C_{\mathrm{D}}}{\partial X^{2}}$

$+K_{\mathrm{D}}\left(C_{\mathrm{D}}-C_{\mathrm{Dm}}\right)=0 \quad X_{1} \leqslant X \leqslant X_{2}$

$\frac{\partial C_{\mathrm{a}}}{\partial \theta}+\gamma_{\mathrm{a}} \frac{\partial C_{\mathrm{a}}}{\partial X}-\frac{\gamma_{\mathrm{a}}}{P_{\mathrm{a}}} \frac{\partial^{2} C_{\mathrm{a}}}{\partial X^{2}}=0 \quad X \geqslant X_{2}$

For the membrane

$\frac{\partial C_{\mathrm{m}}}{\partial \theta}-\frac{1}{P_{\mathrm{m}}} \frac{\partial^{2} C_{\mathrm{m}}}{\partial Y^{2}}=0 \quad 2 \leqslant Y \leqslant 2+2 \Delta$

For the acceptor line

$\frac{\partial C_{\mathrm{f}}^{*}}{\partial \theta}+\gamma_{\mathrm{f}}^{*} \frac{\partial C_{\mathrm{f}}^{*}}{\partial X}-\frac{\gamma_{\mathrm{f}}^{*}}{P_{\mathrm{f}}^{*}} \frac{\partial^{2} C_{\mathrm{f}}^{*}}{\partial X^{2}}=0 \quad X \leqslant X_{1}$

$\frac{\partial C_{\mathrm{A}}}{\partial \theta}+\gamma_{\mathrm{A}} \frac{\partial C_{\mathrm{A}}}{\partial X}-\frac{\gamma_{\mathrm{A}}}{P_{\mathrm{A}}} \frac{\partial^{2} C_{\mathrm{A}}}{\partial X^{2}}-K_{\mathrm{A}}\left(C_{\mathrm{Am}}-C_{\mathrm{A}}\right)=0$

$X_{1} \leqslant X \leqslant X_{2}$

$\frac{\partial C_{\mathrm{a}}^{*}}{\partial \theta}+\gamma_{\mathrm{a}}^{*} \frac{\partial C_{\mathrm{a}}^{*}}{\partial X}-\frac{\gamma_{\mathrm{a}}^{*}}{P_{\mathrm{a}}^{*}} \frac{\partial^{2} C_{\mathrm{a}}^{*}}{\partial X^{2}}=0 \quad X \geqslant X_{2}$
The coefficients $\gamma$ make it possible to use the equations given above for the description of flow systems consisting of sections with various crosssections When all cross-sections have equal $\mathrm{dl}_{1}-$ ameters, the coefficients $\gamma$ are unity

The initial and boundary conditions are the following

For the donor line

$$
\begin{aligned}
& C_{\mathrm{f}}(X, 0)=C_{\mathrm{r}}(X, 0)=C_{\mathrm{D}}(X, 0) \\
& =C_{a}(X, 0)=0 \text {, } \\
& C_{1}(X, 0)=V_{\mathrm{t}} / V_{\mathrm{inj}} \\
& C_{\mathrm{f}}\left(X_{\mathrm{e}}^{-}, \theta\right)=C_{1}\left(X_{\mathrm{e}}^{+}, \theta\right) \\
& C_{\mathrm{f}}\left(X_{\mathrm{e}}^{-}, \theta\right)-\frac{1}{P_{\mathrm{f}}} \frac{\partial C_{\mathrm{f}}\left(X_{\mathrm{e}}^{-}, \theta\right)}{\partial X} \\
& =C_{1}\left(X_{\mathrm{e}}^{+}, \theta\right)-\frac{1}{P_{1}} \frac{\partial C_{1}\left(X_{\mathrm{e}}^{+}, \theta\right)}{\partial X} \\
& C_{1}\left(0^{-}, \theta\right)=C_{\mathrm{r}}\left(0^{+}, \theta\right) \\
& C_{1}\left(0^{-}, \theta\right)-\frac{1}{P_{1}} \frac{\partial C_{1}\left(0^{-}, \theta\right)}{\partial X} \\
& =C_{\mathrm{r}}\left(0^{+}, \theta\right)-\frac{1}{P_{\mathrm{r}}} \frac{\partial C_{\mathrm{r}}\left(0^{+}, \theta\right)}{\partial X}
\end{aligned}
$$$$
C_{\mathrm{r}}\left(X_{1}^{-}, \theta\right)=C_{\mathrm{D}}\left(X_{1}^{+}, \theta\right)
$$

$$
\begin{aligned}
& C_{\mathrm{r}}\left(X_{1}^{-}, \theta\right)-\frac{1}{P_{\mathrm{r}}} \frac{\partial C_{\mathrm{r}}\left(X_{1}^{-}, \theta\right)}{\partial X} \\
& \quad=C_{\mathrm{D}}\left(X_{1}^{+}, \theta\right)-\frac{1}{P_{\mathrm{D}}} \frac{\partial C_{\mathrm{D}}\left(X_{1}^{+}, \theta\right)}{\partial X}
\end{aligned}
$$

$$
C_{\mathrm{D}}\left(X_{2}^{-}, \theta\right)=C_{\mathrm{a}}\left(X_{2}^{+}, \theta\right)
$$$$
C_{\mathrm{D}}\left(X_{2}^{-}, \theta\right)-\frac{1}{P_{\mathrm{D}}} \frac{\partial C_{\mathrm{D}}\left(X_{2}^{-}, \theta\right)}{\partial X}
$$$$
=C_{\mathrm{a}}\left(X_{2}^{+}, \theta\right)-\frac{1}{P_{\mathrm{a}}} \frac{\partial C_{\mathrm{a}}\left(X_{2}^{+}, \theta\right)}{\partial X}
$$

$C_{\mathrm{f}}(-\infty, \theta)=$ finite

$C_{\mathrm{a}}(\infty, \theta)=$ finite 
For the membrane

$C_{\mathrm{m}}(Y, 0)=0$

$\frac{\partial C_{\mathrm{m}}(2, \theta)}{\partial Y}=-H_{\mathrm{D}}\left[C_{\mathrm{D}}(X, \theta)-C_{\mathrm{Dm}}(X, \theta)\right]$

$\frac{\partial C_{\mathrm{m}}(2+2 \Delta, \theta)}{\partial Y}=H_{\mathrm{A}}\left[C_{\mathrm{Am}}(X, \theta)-C_{\mathrm{A}}(X, \theta)\right]$

For the acceptor line

$$
\begin{aligned}
& C_{\mathrm{f}}^{*}(X, 0)=C_{\mathrm{A}}(X, 0)=C_{\mathrm{a}}^{*}(X, 0)=0 \\
& C_{\mathrm{f}}^{*}\left(X_{1}^{-}, \theta\right)=C_{\mathrm{A}}\left(X_{1}^{+}, \theta\right) \\
& C_{\mathrm{f}}^{*}\left(X_{1}^{-}, \theta\right)-\frac{1}{P_{\mathrm{f}}^{*}} \frac{\partial C_{\mathrm{f}}^{*}\left(X_{1}^{-}, \theta\right)}{\partial X} \\
& \quad=C_{\mathrm{A}}\left(X_{1}^{+}, \theta\right)-\frac{1}{P_{\mathrm{A}}} \frac{\partial C_{\mathrm{A}}\left(X_{1}^{+}, \theta\right)}{\partial X} \\
& C_{\mathrm{A}}\left(X_{2}^{-}, \theta\right)=C_{\mathrm{a}}^{*}\left(X_{2}^{+}, \theta\right) \\
& C_{\mathrm{A}}\left(X_{2}^{-}, \theta\right)-\frac{1}{P_{\mathrm{A}}} \frac{\partial C_{\mathrm{A}}\left(X_{2}^{-}, \theta\right)}{\partial X} \\
& \quad=C_{\mathrm{a}}^{*}\left(X_{2}^{+}, \theta\right)-\frac{1}{P_{\mathrm{a}}^{*}} \frac{\partial C_{\mathrm{a}}^{*}\left(X_{2}^{+}, \theta\right)}{\partial X} \\
& C_{\mathrm{f}}^{*}(-\infty, \theta)=\text { finite } \\
& C_{\mathrm{a}}^{*}(\infty, \theta)=\text { finite }
\end{aligned}
$$

The superscripts - and + refer to the upstream and downstream side, respectively, of a given interface between two adjacent flow sections

The empirical parameters of the model are the Peclet numbers of the different sections and the mass-transfer coefficients in both channels of the membrane separation module The other parameters of the model are etther fundamental constants (e $g$, diffusion coefficient in the membrane) or physical parameters, some of which can be measured ( $\mathrm{g}$, geometncal dimensions, flowrates) It should be pointed out that the membrane when contacting with solutions usually swells and its thickness under workıng conditıons cannot be measured easily There are theoretical and empirical relationships for calculating the laminar Peclet numbers of certain type of reactors (e g , straight and coiled tubes), valid usually for the case of diffusion-controlled dispersion [16] In most of the flow-injection systems an injection valve is used In this instance the injection section includes the sample loop and the internal bores of the valve, thus having a rather complex geometry Therefore, its Peclet number can be determined experimentally only However, it has been found that if the volume of the injection section is considerably smaller than the reactor volume (e $g$, less than $10 \%$ of $1 \mathrm{t}$ ), which is frequently the case, the Peclet number of the injection section can be assumed to be equal to that of the reactor [17] For volumes of the injection section of less than $3 \%$ a delta-function approximation can be used, which considerably simplifies the solution of the model [17] Theoretieal relationships have been derived for calculating the Peclet number and the mass-transfer coefficients in both channels of parallel-plate dialysers under laminar flow conditıons $[20,21]$

\section{Solution of the model}

Equations 3-11 were solved by means of the Laplace transform technique

$$
\bar{C}(X, Y)=\int_{0}^{\infty} C(\theta, X) \exp [-p \theta] \mathrm{d} \theta
$$

In the Laplace domain these equations reduce to ordinary linear differential equations of the second order, which were solved analytically (Appendix A) Interesting points for monitoring the concentration are the inlet and outlet of the donor channel and the outlet of the acceptor channel in the case of both seml-permeable and impermeable membranes The corresponding Laplace domain solutions of mass transfer in the membrane separation module are presented in Appendix A for threc different cases (1) overall transfer is governed by transfer in the channels and in the membrane; (11) overall transfer is governed by transfer in the membrane only ( $1 \mathrm{e}$, infinitely high mass-transfer coefficients), and (i1) only transfer in the channels is of importance 
(1 e, infinitely thın membrane or infinitely high diffusion coefficient within it) The time domain solutions were obtained by numerical inverse transformation of the corresponding Laplace domain solutions by expansion of the latter into Fourier sine series and subsequent analytical inverse transformation [23]

For high Peclet numbers of the reactor and the channels of the separation module (e $\mathrm{g}, P>$ 120), the numerical technique described above does not give satisfactory results The concentration curves are lower and exhibit oscillating fronts and tails Taking into consideration that at high Peclet numbers the "end effects" are negligible [22], it can be assumed that the flow pattern in the membrane separation module does not affect the overall dispersion process in the reactor This allows one to describe the concentration profile at the inlet of the donor channel as if the reactor is infinitely long For a straight tube reactor in the case of diffusion-controlled dispersion ( $1 \mathrm{e}$, $\tau>07$, Eqn 2) and small sample volume, so that the injection section can be considered as part of the reactor, the corresponding analytical solution of Eqn 5 will be the following [24]

$$
\begin{aligned}
C\left(\theta, X_{1}\right)= & \frac{1}{2}\left\{\operatorname{erf}\left[\frac{\gamma_{\mathrm{r}} \theta-X_{1}}{2\left(\gamma_{\mathrm{r}} \theta / P_{\mathrm{r}}\right)^{1 / 2}}\right]\right. \\
& \left.+\operatorname{erf}\left[\frac{X_{1}-X_{\mathrm{e}} \gamma_{\mathrm{r}} / \gamma_{1}-\gamma_{\mathrm{r}} \theta}{2\left(\gamma_{\mathrm{r}} \theta / P_{\mathrm{r}}\right)^{1 / 2}}\right]\right\}
\end{aligned}
$$

where erf is the error function

Equation 16 defines the input concentration profile for the membrane separation module The equations describing the processes taking place in the two channels of the membrane separation module and in the membrane itself (1 e , Eqns 6, 8 and 10) can be solved by the implicit alternating-direction finite-difference method [25] The corresponding finite-difference equations are given in Appendix B The concentration profiles monitored downstream of the outlet of the donor (Eqn 17) and the acceptor (Eqn 18) channels (Fig 1) can be calculated on the basis of the convolution theorem

$$
\begin{aligned}
& C(\theta, X) \\
& =\left(\frac{P_{\mathrm{a}}}{4 \pi \gamma_{\mathrm{a}}}\right)^{1 / 2} \int_{0}^{\theta} C_{\mathrm{D}}\left(\theta, X_{2}\right)(\theta-\phi)^{-1 / 2} \\
& \quad \times \exp \left[-P_{\mathrm{a}} \frac{\left(X-X_{2}-\gamma_{\mathrm{a}}(\theta-\phi)\right)^{2}}{4 \gamma_{\mathrm{a}}(\theta-\phi)}\right] \mathrm{d} \phi \\
& C(\theta, X) \\
& =\left(\frac{P_{\mathrm{a}}^{*}}{4 \pi \gamma_{\mathrm{a}}^{*}}\right)^{1 / 2} \int_{0}^{\theta} C_{\mathrm{A}}\left(\theta, X_{2}\right)(\theta-\phi)^{-1 / 2} \\
& \quad \times \exp \left[-P_{\mathrm{a}}^{*} \frac{\left(X-X_{2}-\gamma_{\mathrm{a}}^{*}(\theta-\phi)\right)^{2}}{4 \gamma_{\mathrm{a}}^{*}(\theta-\phi)}\right] \mathrm{d} \phi
\end{aligned}
$$

where $C_{\mathrm{D}}\left(\theta, X_{2}\right)$ and $C_{\mathrm{A}}\left(\theta, X_{2}\right)$ are the numer1cal solutions of Eqns 6,8 and 10, and Eqn 19 is the solution of the axially dispersed plug flow model in the case of an infinitely long tube and delta-function injection at $X=X_{2}$

$$
\begin{aligned}
C(\theta, X)= & \left(\frac{P}{4 \pi \gamma \theta}\right)^{1 / 2} \\
& \times \exp \left[-P \frac{\left(X-X_{2}-\gamma \theta\right)^{2}}{4 \gamma \theta}\right]
\end{aligned}
$$

\section{EXPERIMENTAL}

\section{Flow-injection manifold}

The main geometrical dimensions of the experimental flow system used in this work, and presented schematically in Fig 2, are summarized in Table 2

A constant flow-rate in both the donor and the acceptor lines was maintained by a low-pulsation computer-controlled perıstaltıc pump (Minıpuls, Gison) To reduce further the undesirable effects caused by pulsation and to remove the air bubbles from the donor and the acceptor streams, pulse dampers were installed downstream of the 
A
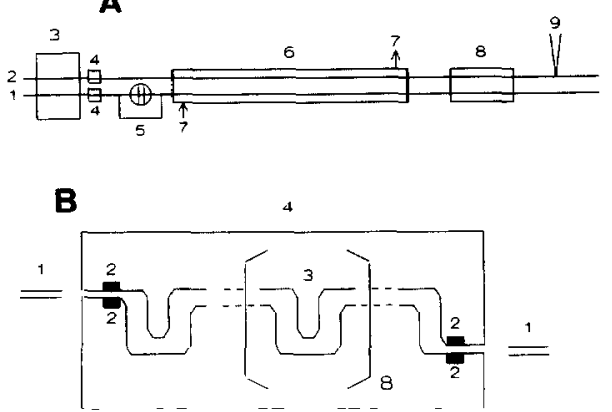

Fig 2 (A) Scheme of the experimental manifold $1=$ Donor line, $2=$ acceptor line, $3=$ peristaltic pump, $4=$ pulse dampers, $5=$ injection valve, $6=$ thermostating Perspex tube, $7=$ thermostating water, $8=$ dialysis module, $9=$ thermocouple (B) Scheme of one of the halves of the dialysis module 1 = PTFE tubes, 2 = platınum electrodes, $3=$ element of the channel, repeated eight consecutive tımes, $4=$ Perspex body

pump (Fig 2) One of their walls consists of a gas-permeable membrane made by stretchıng a PTFE foll The flow-rates in both lines were determined for each experıment by collectıng and weighing their effluents over intervals of $5 \mathrm{~min}$ The total lengths of the tubings of both lines were chosen to be almost equal to prevent a pressure difference between the two channels in the dialysers, which may cause deformation of the membrane, makıng the mass-transfer process more complicated The flow-rates in the two lines of the manifold during all the experiments did not differ by more than $1 \%$

An automatic computer-controlled rotary injection valve (Universal, Anachem) with an external sample loop was used The latter was a bent piece of PTFE tubing It was assumed that the whole sample volume filling the external loop and some of the internal bores of the valve were situated in the external loop only On this basis, the length of the external loop, which corresponds in this instance to the injection section in the model (Frg 1), was recalculated (Table 2)

The fore-sections, the after-sections and the reactor were PTFE tubes Their inside diameters were determined by the volume of doubly distilled water with which they can be filled The reactor was a straight tube The sections of the fore- and after-sections adjacent to the valve and the dialysis module were also straight tubes Their lengths were chosen in such a way that the socalled "end effects" could be neglected [22]

A parallel-plate dialyser made of two Perspex halves with a meander-type rectangular groove (Fig 2A) was used The membrane was placed between the two halves before they were screwed together The bottom of each groove was roughened by milling into small circles, thus creatıng turbulence promoters for intensifying the mass transfer in the channels Short rectangular channels ( $5 \mu \mathrm{l}$ each) connected the grooves of the dialyser with the PTFE tubes by ferrules and screws Their volumes were considered in the calculations as parts of the corresponding adjacent flow sections (Fig 1) Platınum plates $(08 \times$ $08 \mathrm{~mm}$ ) were installed parallel to each other in the bores next to the grooves (Fig 2a) They allowed the conductivity (PW9509 digital conductivity meter, Philips) of the influent and effluent of both the donor and the acceptor channels of the dialyser to be monitored

Two types of hydrophilic membrane were used in the experiments, $1 \mathrm{e}$, a PTFE membrane ımpermeable to potassium chloride and a permeable cellulose hydrate Cuprophan (Enka Glanzstoff) membrane

The flow system was kept at $200 \pm 01^{\circ} \mathrm{C}$ The thermostating system consisted of a thermostat (P M Tamson) and a straight Perspex tube in which the reactor and the fore-section of the acceptor line were installed and through which water at the above temperature was constantly

TABLE 2

Geometrical dimensions of the manifold

\begin{tabular}{|c|c|c|c|c|}
\hline \multirow[t]{2}{*}{ Section } & \multicolumn{2}{|c|}{ Donor lıne } & \multicolumn{2}{|c|}{ Acceptor line } \\
\hline & $\begin{array}{l}\text { Length } \\
\text { (m) }\end{array}$ & $\begin{array}{l}\text { Diameter } \\
(\mathrm{mm})\end{array}$ & $\begin{array}{l}\text { Length } \\
\text { (m) }\end{array}$ & $\begin{array}{l}\text { Diameter } \\
(\mathrm{mm})\end{array}$ \\
\hline Fore-section & 0500 & 05304 & 2950 & 05304 \\
\hline Injection section & 0115 & 05304 & & \\
\hline Reactor & 2487 & 05304 & & \\
\hline Channel a & 0166 & $02405^{b}$ & 0166 & $02590^{b}$ \\
\hline After-section & 0540 & 05304 & 0450 & 05304 \\
\hline
\end{tabular}

a The width of both channels is $00030 \mathrm{~m}{ }^{\mathrm{b}}$ Height of the channels 
circulating The source bottles containing the carner solutions for the donor and the acceptor lines were placed in the basin of the thermostat The temperature of the acceptor stream was controlled by a platınum-platınum/rhodium thermocouple connected to a microvoltmeter (3478A Multımeter, Hewlett Packard) (Fig 2)

The experimental manifold described above was operated by an Apple IIG computer The software was written in Fysforth version 03 The data readings from the conductivity meter and the microvoltmeter were collected and transferred to an IBM-compatible PC for further processing

\section{Reagents}

Standard solutions of potassium chlonde in doubly distilled water with concentrations in the range $10 \times 10^{-4}-10 \times 10^{-2} \mathrm{M}$ were used for injection, calibration and as carrier solutions in the steady-state experiments

\section{Procedure}

The stımulus-response technique [10] was used for identification of the unknown parameters in the model outlined in this paper under flow-injection conditions The tracer injected by the valve was a $10 \times 10^{-2} \mathrm{M}$ solution of potassium chlonde The carner solutions in both lines, if not stated otherwise, were doubly distilled water

Three series of experiments were performed as follows In the first series, the membrane (PTFE foil) installed in the dialysis module was impermeable to the tracer (potassium chloride) The response curves at the inlet and outlet of the donor channel were monitored at four different flow-rates in the range $01-10 \mathrm{ml} \mathrm{min}{ }^{-1}$ For investigating the acceptor channel its position was interchanged with that of the donor channel, thus connecting it to the reactor The same experimental procedure was performed again

In the second series of experiments, the impermeable PTFE foll was replaced by Cuprophan membrane, permeable to the tracer The response curves at the inlet and outlet of the donor channel and at the outlet of the acceptor channel were recorded at different flow-rates in the range 0 1-0 $5 \mathrm{ml} \mathrm{min}{ }^{-1}$ For higher flow-rates the mass transfer under the working conditions used became negligible

In the third series, doubly distilled water was maintained as the carrier solution in the acceptor line while the carrier solution in the donor line was $16 \times 10^{-3} \mathrm{M}$ potassum chlonde solution The steady-state concentrations at the outlets of both channels of the dialyser and at the inlet of the donor channel were measured at different flow-rates ranging from 01 to $05 \mathrm{ml} \mathrm{min}{ }^{-1}$ as in the second series of experiments

Calibration graphs for all four conductivity detectors were obtained on the basis of fourteen standard solutions of potassium chlonde (0 0-2 2 $\left.\times 10^{-3} \mathrm{M}\right)$ The relationship between concentration and conductance was described by polynomial regression equations of the second power It was found that the flow-rate had no effect on the calibration graphs

\section{Processing of the expenmental response curves}

The unknown parameters of the model are the Peclet numbers in all eight flow sections (Fig 1), the mass-transfer coefficients of the donor and the acceptor channels, the diffusion coefficient and the thickness of the Cuprophan membrane As already pointed out, the lengths of the foreand after-sections were chosen such that their Peclet numbers (Eqn 2) can be determined according to Taylor's theory $[18,19]$ The volume of the tracer injected in each experiment was less than $5 \%$ of the characteristic volume $\left(V_{t}\right)$ (Table 2) In such a case the overall dispersion process should depend only slightly on the Peclet number of the injection section [17] and the latter can be assumed to be equal to that of the reactor The flow-rates used in the experiments corresponded to Fourier numbers of the reactor $\left(\tau_{\mathrm{r}}\right)$ well above 07 , which made it possible to apply Eqn 2 for the calculation of the Peclet number On the basis of the above considerations, the eight unknown Peclet numbers could be reduced to three unknown parameters, $1 \mathrm{e}$, the Peclet numbers of the donor and the acceptor channels and the diffusion coefficient of potassium chloride in doubly distilled water at $20^{\circ} \mathrm{C}$ The last parameter was necessary for calculatıng the remainder of the Peclet numbers of the flow system according 
to Eqn 2 In fact, these three parameters are the only unknown parameters of the model under the assumptions made above in the case of an impermeable membrane ( $1 \mathrm{e}$, first series of exper1ments) From the response curves detected in the donor line before and after the donor or the acceptor channels, it was possible to determine the diffusion coefficient of the tracer in the liquid phase and the axial dispersion coefficients of both channels at different flow-rates The other unknown parameters of the model, $1 \mathrm{e}$, the mass transfer in the channels and within the membrane, were determined form the response curves monitored at the outlet of the donor and the acceptor channels in the second series of exper1ments (with the Cuprophan membrane) The results obtained were used to derive empinical relationships for the calculation of the mass-transfer and axial dispersion coefficients for both channels

The values of the steady-state concentrations at the outlets of both channels measured at different flow-rates can be used for calculating the permeability of the Cuprophan membrane The appropriate equations are given in Appendix C For each flow-rate, the permeability of the membrane was determined as the average of the permeabilities based on the steady-state concentrations measured in donor and acceptor channels (Appendix C) In these calculations, the masstransfer and axial dispersion coefficients (Peclet numbers) of the two channels of the dialyser were calculated by the relationshıps derived earher The proper functioning of the manifold was controlled by monitoring the tracer concentration at the inlet of the donor channel, which should be constant durıng all steady-state experıments

Curve fitting was utilized to determine the unknown parameters when the tracer response curves were processed ( $1 \mathrm{e}$, in the furst two series of experiments) A simplex optimization method based on the algorithm of Nelder and Mead [26] was used The function minimized by this procedure was the square root of the mean squared error between experimental and theoretical response curves Only those parts of the response curves where the concentration was greater than $5 \%$ of the maximum concentration were used in the calculations, thus saving computational time and excluding the less informative sections in the front and the tall of the experimental response curves The zeroth and first statistical moments about the origin (Eqn 20, $J=0$ and $\jmath=1$ ) and the second moment about the mean (Eqn 21) of the experimental response curves and of their best theoretical fits were calculated and compared

$\mu_{j}=\int_{0}^{\infty} C \theta^{\jmath} \mathrm{d} \theta$

$\sigma^{2}=\int_{0}^{\infty} C\left(\mu_{1}-\theta\right)^{2} \mathrm{~d} \theta=\mu_{2}-\mu_{1}^{2}$

It is possible to calculate the statistical moments directly from the Laplace domain solution of the model (Appendix A) without the necessity of performing its inverse transformation by the following relationship, proposed by Van der Laan [27]

$\mu_{J}=(-1)^{-J}\left(d^{J} \bar{C} / \mathrm{d} p^{J}\right)_{p \rightarrow 0}$

The zeroth moments for the donor and the acceptor channels define the integral amount of tracer monitored in them They are interrelated by the following equation

$\mu_{0_{\mathrm{D}}}+\left(v_{\mathrm{A}} / v_{\mathrm{D}}\right) \mu_{0_{\mathrm{A}}}=1$

This relationship was used for controlling the manifold for malfunctioning during the exper1ments The first moment about the origin (Eqn $20, J=1$ ), known as the mean, defines the centre of gravity of the tracer response curve The second moment about the mean, known as the var1ance, (Eqn 21) characterizes the width of the tracer response curve and can be used for determining the sample throughput of the manifold

\section{Computer programs}

The numerical procedures outlined above for processing of the tracer response curve and for solving the model were programmed in QuickC (Version 2, Microsoft) and the corresponding programs were run on an IBM-compatible PC 


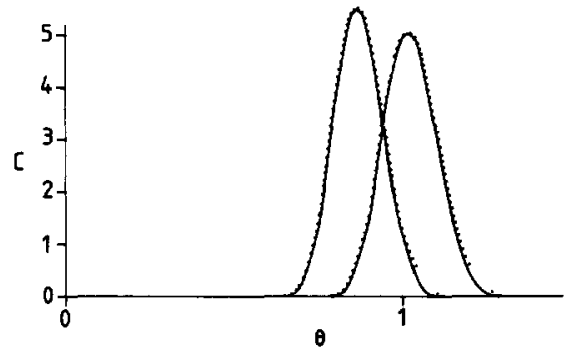

Fig 3 Comparison of experimental tracer response curves (solid lines) measured at $0133 \mathrm{ml} \mathrm{min}{ }^{-1}$ before and after the donor channel and their best theoretical fits (dotted lines)

\section{RESULTS AND DISCUSSION}

Determination of the diffusion coefficient of the tracer in the flow system and its axial dispersion coefficients in the channels of the dialyser

Figure 3 illustrates the agreement between the experimental response curves from the first series of experiments (with the impermeable membrane) and their best theoretical fits

The diffusion coefficient of potassium chloride obtained from the Peclet number of the reactor (Eqn 2) by the curve-fittıng procedure, outlined earlier was found to be $172 \times 10^{-9} \mathrm{~m}^{2} \mathrm{~s}^{-1}$, which was fairly close to earlier results [15] and to literature data $\left(177 \times 10^{-9} \mathrm{~m}^{2} \mathrm{~s}^{-1}\right.$ at infinite dilution [28]) Very slight variations in this value (less than 3\%) were observed for different flowrates in the range 01-10 ml min ${ }^{-1}$ Because the geometry of the dialyser channels is complicated, no theoretical relationships similar to Eqn 2 for

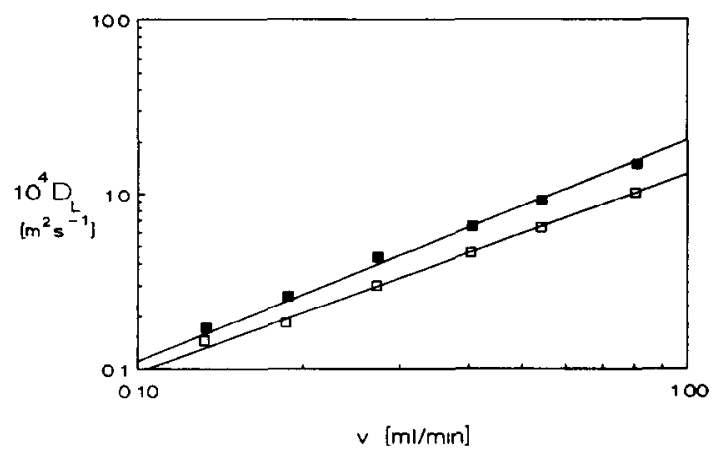

Fig 4 Axıal dispersion coefficient versus flow-rate in ml $\mathrm{min}^{-1}$ for the ( $\square$ ) donor and ( $\square$ ) acceptor channels calculating the corresponding axial dispersion coefficients or Peclet numbers exist It was found that the flow-rate dependence of the axial dispersion coefficients can be described successfully (Fig 4) by the following empirical equations

$D_{\mathrm{L}_{\mathrm{D}}}=1531 \times 10^{6} v_{\mathrm{D}}^{12692}$
$D_{\mathrm{L}_{\mathrm{A}}}=9865 \times 10^{4} v_{\mathrm{A}}^{11414}$

Determination of the mass-transfer coefficients in the channels of the dialyser, the thickness of the membrane and the diffusion coefficient of the tracer withun it

The tracer response curves obtained in the second series of experiments were processed by curve-fitting for determining the values of the following parameters of the model $K_{\mathrm{D}}, K_{\mathrm{A}}, P_{\mathrm{m}}$ and $\Delta$ From the last two parameters the thickness of the membrane and the effective diffusion coefficient of potassium chloride withın it at $20^{\circ} \mathrm{C}$ can be easily calculated In the calculations all the Peclet numbers in the model were calculated by using Eqn 2 and Eqns 24 and 25 In the second series of experiments, the flow-rate in both lines of the manıfold was varied $\left(\begin{array}{ll}0 & 1-0\end{array}\right.$ min $^{-1}$ ), thus changing the hydrodynamimc conditıons in both channels of the dialysis module It can be expected that the corresponding masstransfer coefficients will vary also with the flowrate while the thickness of the membrane $(2 \delta)$ and the diffusion coefficient of the tracer within It $\left(D_{\mathrm{m}}\right)$ should remain unchanged The expernmental results showed that $2 \delta$ and $D_{\mathrm{m}}$ obtained for four different flow-rates were within $3 \%$ of the their mean values (Table 3), 1 e , $2808 \times 10^{-5}$ $\mathrm{m}$ and $7915 \times 10^{-11} \mathrm{~m}^{2} \mathrm{~s}^{-1}$, respectively This result confirms the validity of the model The

TABLE 3

Curve-fittıng results for $2 \delta$ and $D_{\mathrm{m}}$

\begin{tabular}{lll}
\hline$v_{\mathrm{D}}\left(\mathrm{ml} \mathrm{mn^{-1 } )}\right.$ & $2 \delta(\mu \mathrm{m})$ & $10^{11} D_{\mathrm{m}}\left(\mathrm{m}^{2} \mathrm{~s}^{-1}\right)$ \\
\hline 01016 & 2762 & 7747 \\
01917 & 2808 & 8141 \\
02803 & 2830 & 7892 \\
04153 & 2832 & 7880 \\
Average & 2808 & 7915 \\
\hline
\end{tabular}




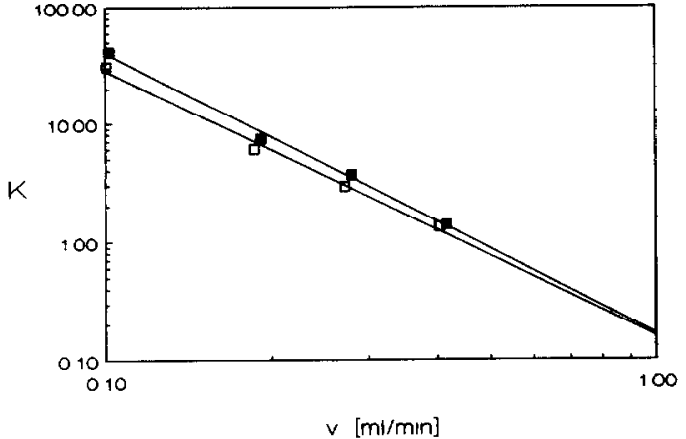

Fig 5 Mass-transfer coefficient versus flow-rate in $\mathrm{ml} \mathrm{min}^{-1}$ for the ( $\square$ ) donor and ( $\square$ ) acceptor channels

thickness of the membrane $(2 \delta)$ before contacting with water (normal state) is stated by the producer to be $13 \times 10^{-5} \mathrm{~m}$ Its increase during the transition from the normal to the wet state due to swelling is reported to amount to a factor of 19 This will result in a $2 \delta$ value of $248 \times 10^{-5} \mathrm{~m}$, which is close to the value obtained in the present investigation This fact could be considered as further proof for the adequacy of the model outlined earlier The values obtained for the mass-transfer coefficients of the channels for different flow-rates were found to obey fairly well the following relationships (Fig 5)

$K_{\mathrm{D}}=4854 \times 10^{-20} v_{\mathrm{D}}^{-2382}$

$K_{\mathrm{A}}=3465 \times 10^{-19} v_{\mathrm{A}}^{-2270}$

The satısfactory agreement between the experimental response curves and their best theoretical fits is illustrated in Fig 6

Determination of the permeability of the membrane under steady-state conditions

The steady-state concentrations measured at the outlets of the donor and the acceptor channels for different flow-rates are presented in Fig 7

Under steady-state conditions, the thickness of the membrane and the diffusion coefficient of the tracer within it cannot be determined separately from each other, because only the ratio of these two parameters appears in the equations describing the steady-state mass transfer through the membrane (Appendix C) For this reason, the

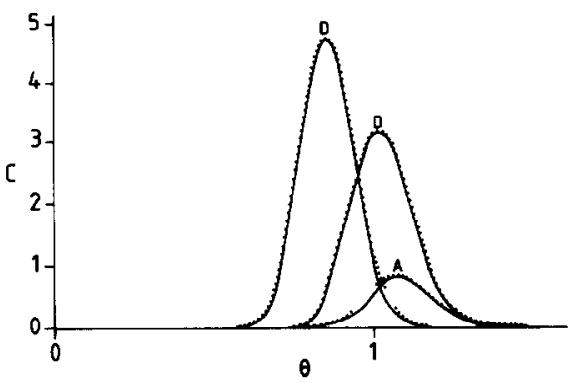

Fig 6 Experimental tracer response curves (solıd lines) measured at $v_{\mathrm{D}}=0190 \mathrm{ml} \mathrm{min}-1$ and $v_{\mathrm{A}}=0187 \mathrm{ml} \mathrm{min}^{-1}$ before the donor channel and after the donor and the acceptor channels and their best model fits (dotted lines) D and A refer to the donor and acceptor lines, respectively

experimental results obtained in this series of experiments were used for determining the ratio $D_{\mathrm{m}} / 2 \delta$, which is often referred to as the permeability of the membrane The value of the permeability, averaged over the whole range of flowrates, was found to be $235 \times 10^{-6} \mathrm{~m} \mathrm{~s}^{-1}$, which does not differ substantially from the correspondIng value obtained under flow-injection conditions, $1 \mathrm{e}, 282 \times 10^{-6} \mathrm{~m} \mathrm{~s}^{-1}$ This result is further proof of the validity of the model Permeability data for Cuprophan membranes with thickness $115 \times 10^{-6}$ and $135 \times 10^{-6} \mathrm{~m}$, when a $001 \mathrm{M}$ solution of sodium chloride at $20^{\circ} \mathrm{C}$ was used, were provided by the manufacturer According to the manufacturer, the membrane used in the present experiment had a thickness of $127 \times 10^{-6} \mathrm{~m}$ For this membrane the perme-

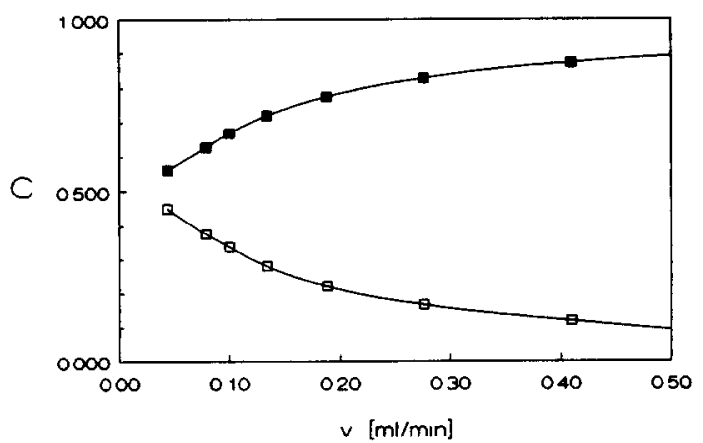

Fig 7 Steady-state concentration versus flow-rate $1 \mathrm{~m} \mathrm{ml} \mathrm{min}{ }^{-1}$ measured downstream of the $(\square)$ donor and ( $\square$ ) acceptor channels 
ability was calculated by interpolation to be (4 66 $\pm 064) \times 10^{-6} \mathrm{~m} \mathrm{~s}^{-1}$, which is at least of the same order of magnitude as the values obtained in the present study Because the details of the experumental procedure for determining the permeability by the manufacturer are lacking and a different electrolyte at a different concentration is used, it is impossible to assess the causes of the discrepancy

Influence of system parameters on sensitivity and sample throughput

After having proved the validity of the model, it is possible to investigate by numerical simulations the influence of the main design and operational parameters of a flow-injection system with a membrane separation module on the sensitivity and sample throughput of analysis In this way costly and time-consuming experiments could be avoided For convenience, the parameters of the experumental flow system outlıned above could be used in the simulations This will make it possible in some instances to compare simulated with expenmental results As the empinical flow-rate dependence of the axial dispersion and masstransfer coefficients in the channels of the dialysis module was determined in the range $0-10 \mathrm{ml}$ $\mathrm{min}^{-1}$ for the former and $0-05 \mathrm{ml} \mathrm{min}{ }^{-1}$ for the latter coefficients, the simulations were confined to the narrower flow range In an earlier study, the influence of the main parameters of a parallel-plate dialyser under laminar flow conditions was thoroughly investigated and conclusions for choosing their optimum values with respect to mass-transfer efficiency were drawn [21] The calculations performed for a pulse concentration input were made under the assumption of zero length of the reactor and no dispersion in the injection section Neither of these conditions holds in real flow-injection manifolds For this reason, it is expedient to investigate how the dispersion processes in the flow sections upstream of the donor channel ( $1 \mathrm{e}$, fore-section, injection section and reactor) and the sample volume $\left(-X_{\mathrm{e}}\right)$ will influence the peak height $\left(c_{\max }\right.$ or $C_{\max }$ ) and the peak broadening ( $e$ or $E$ ) of the concentration profile monitored at the outlet of the acceptor channel For flow systems with rela-

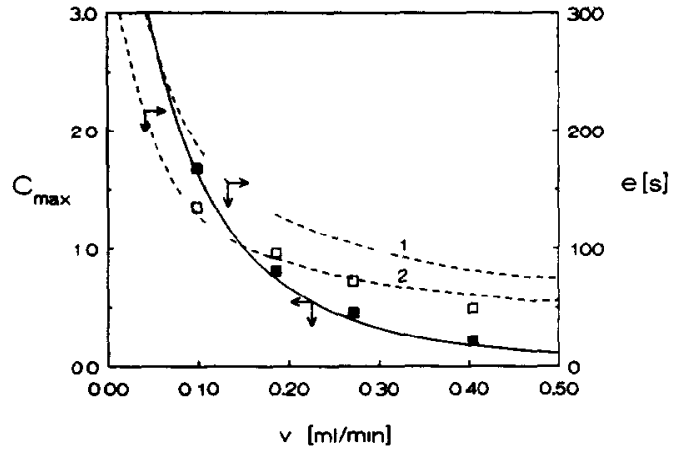

Fig 8 Flow-rate dependence of the maximum concentration $\left(C_{\max }\right)$ in the acceptor channel (solid line) and the peak width (dotted lines) at (1) $001 C_{\max }$ and (2) $01 C_{\max }$ Experimental results for ( $\square$ ) $C_{\max }$ and ( $\square$ ) for the peak width at $01 C_{\max }$

tively small sample volumes, the dispersion of the analyte in the reactor is the process playing a major role in the formation of the concentration profile at the inlet of the donor channel [17] This process can be characterized by the reactor Fourier number $\left(\tau_{\mathrm{r}}\right)$

$\tau_{\mathrm{r}}=\pi D_{\mathrm{r}} x_{1} / v_{\mathrm{D}}$

From Eqn 28, it follows that concentration profile at the inlet of the donor channel for a given analyte can be easily manipulated by varying the volumetric flow-rate or (and) the length of the reactor The volumetric flow-rate in the acceptor channel was assumed to be equal to that in the donor line (as in the expenmental man1fold) The flow-rate $v_{\mathrm{D}}$ is an operational parameter affecting considerably the dispersion processes in all sections of the flow system (including the channels of the dialysis module) and the rate of mass transfer Its effect on peak height and peak broadening is illustrated in $F_{1 g} 8$ The peak broadening $(e)$ is given in real dimensions ( $\mathrm{e}$, in seconds) to avoid confusion originating from the fact that on changing the flow-rate the mean residence tıme, which is the dimensionless time unit, also changes The flow-rate dependences of $C_{\max }$ and $e$ (at both $001 C_{\max }$ and $01 C_{\max }$ ) are similar, showing that in choosing the flow-rate a compromise should be made between sensitivity and sample throughput The comparison of the theoretically calculated relationships for the flow-rate dependence of the maximum $C_{\mathrm{A}}$ and 
the peak width (at $C_{\mathrm{A}}$ equal to $10 \%$ of the maximum $C_{\mathrm{A}}$ ) with experimental results shows a satisfactory agreement ( $\mathrm{F}_{1} \mathrm{~g}$ ) The agreement for $e$ measured at $1 \%$ of the maximum $C_{\mathrm{A}}$ was poor because the signal monitored for such low concentrations $\left(10^{-6}-10^{-5} \mathrm{M}\right)$ was in the range of the noise of the conductivity meter used

The influence of the reactor length $\left(x_{1}\right)$ on $c_{\max }$ and $e$ (at $1 \%$ of $c_{\max }$ ) at a constant flow-rate (02 $\mathrm{ml} \mathrm{min}^{-1}$ ) is illustrated in Fig 9 These results show that shorter reactors are more favourable for the optımum performance of the flow-injection manifolds considered in this study However, it should be taken into consideration that a longer reactor can improve to a certain extent the reproducibility of analysis The reason for this is that the greater the extent to which the dispersion process is diffusion controlled ( $1 \mathrm{e}$, high $\tau$ ), the smaller is the influence or arbitrary disturbances in the flow (e $g$, slight variation in the flow-rate, pulsations) on the detected signal

The influence of the sample volume $\left(-X_{\mathrm{e}}\right)$ on the acceptor peak maximum $\left(c=-c_{0} / \gamma_{1} X_{e} C_{\max }\right.$, where $c_{0} / \gamma_{1}$ is constant throughout the simulations) and on the peak width (at $1 \%$ of $c_{\max }$ ) is presented in Fig 10 For simplicity in the calculations, the axial dispersion coefficient in the injection section was assumed to be equal to that of the reactor even for relatively large sample volumes ( $1 \mathrm{e},-X_{\mathrm{e}}>0$ 1) As expected, an increase in the sample volume leads to a higher peak maximum and hence to a higher sensitivity of analysis The dependence is almost linear for

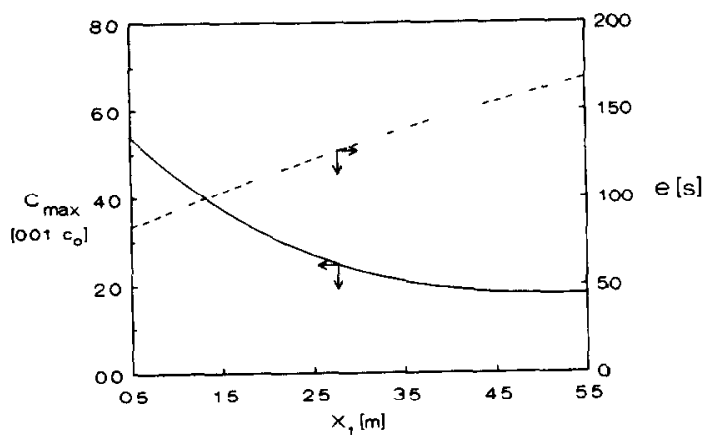

Fig 9 Influence of the reactor length $\left(x_{1}\right)$ on $c_{\max }$ (solid line) and $e$ at $001 c_{\max }$ (dotted line) $v_{\mathrm{D}}=02 \mathrm{ml} \mathrm{min}^{-1}$

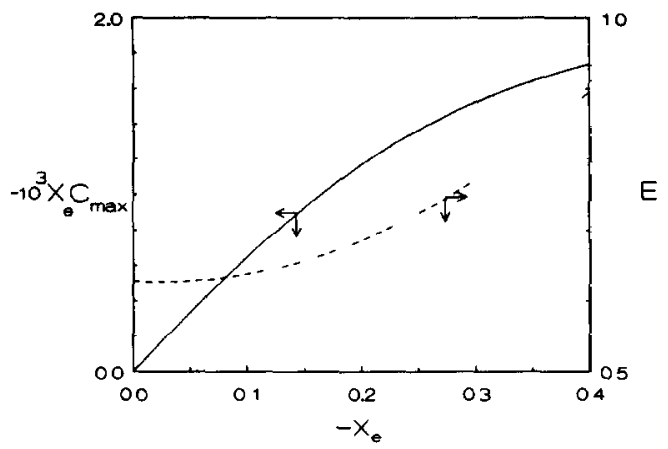

F1g 10 Influence of the sample volume $\left(-X_{\mathrm{e}}\right)$ on $c_{\max }$ (solid line) and $e$ at $001 c_{\max }$ (dotted line) $V_{D}=02 \mathrm{ml} \mathrm{min}^{-1}$

dimensionless sample volumes up to 02 , above which the slope gradually decreases and $C_{\mathrm{A}}$ approaches asymptotically the steady-state acceptor concentration for volumes higher than 08 [21] In the linear range mentioned above $\left(-X_{\mathrm{e}}<02\right)$, the sample volume has virtually no influence on the sample throughput of the manifold For larger sample volumes the baseline-to-baseline time increases with $-X_{\mathrm{e}}$ These results show that choosing a sample volume in the upper part of the linear range (e g, $01-02$ ) seems to be appropriate with respect to both sensitivity and sample throughput

\section{Conclusions}

A general mathematical model for a flow-1njection system with a dialysis module based on the axially dispersed plug flow model was developed It was solved by Laplace transforms for values of the reactor Peclet number of less than 120 , whereas for higher values a numerical method using the implicit alternating-direction finite difference method was found to be more suitable

The validity of the model was confirmed experimentally for a flow-injection manifold utılizing a parallel-plate dialysis model This geometry of the dialyser does not limit the generality of the model, which can also be applied to other geometries of the membrane separation module (e $\mathrm{g}$, tubular) and other types of membranes (e $g$, gasdiffusion) 
The results obtained in this study show that the proposed model for a flow-injection manifold with a membrane separation module, together with the parameter identification procedure outlined above, can be used successfully for a better understanding of the processes taking place in such manifolds and for predicting the shape and magnitude of the analytical signal, for optımızing the performance of these manifolds with respect to sensitivity and sample throughput, for characterizing various membranes ( $1 \mathrm{e}$, determining their thickness and the diffusivity of different analytes in them) and for characterizing the mass-transfer properties of various geometries of the donor and the acceptor channels (1 e , determining their axial dispersion and mass-transfer coefficients) The last two possible applications of the model could be useful in membrane technology and in designing effective process, medical (for haemodialysis) or analytical flow-through dialysers

The possibility provided by simulating the model to select the values of some construction and operational parameters of the flow-injection systems incorporating membrane separation modules which will ensure their optımum performance is illustrated on the experimental manıfold used for verification of the model On the basis of the simulation results, some more general conclusions concerning the selection of optimum sample volume and reactor length were drawn the sample volume $\left(-X_{\mathrm{e}}\right)$ should be in the range 0 1-0 3 and the reactor length should not exceed the value necessary for obtainıng a reproducible concentration profile at the inlet of the donor channel The last condition is usually in effect for diffusion-controlled dispersion $\left(\tau_{r}>07\right)$ The guidelınes for choosing optimum values for the parameters of the membrane separation module were formulated elsewhere [21]

The authors are grateful to Egbert Hoogendam for experımental help

\section{APPENDIX A}

\section{Laplace domain solution of Eqns 3-11}

The Laplace transforms of Eqns 3-11 are the following

For the donor line

$$
\begin{aligned}
& \frac{\mathrm{d}^{2} \bar{C}_{\mathrm{f}}}{\mathrm{d} X^{2}}-P_{\mathrm{f}} \frac{\mathrm{d} \bar{C}_{\mathrm{f}}}{\mathrm{d} X}-\frac{p P_{\mathrm{f}}}{\gamma_{\mathrm{f}}} \overline{C_{\mathrm{f}}}=0 \quad X \leq X_{\mathrm{e}} \\
& \frac{\mathrm{d}^{2} \bar{C}_{1}}{\mathrm{~d} X^{2}}-P_{1} \frac{\mathrm{d} \bar{C}_{1}}{\mathrm{~d} X}-\frac{p P_{1}}{\gamma_{\mathrm{l}}} \overline{C_{1}}=-\frac{P_{1}}{\gamma_{\mathrm{l}}} \quad X_{\mathrm{e}} \leq X \leq 0 \\
& \frac{\mathrm{d}^{2} \overline{C_{\mathrm{r}}}}{\mathrm{d} X^{2}}-P_{\mathrm{r}} \frac{\mathrm{d} \bar{C}_{\mathrm{r}}}{\mathrm{d} X}-\frac{p P_{\mathrm{r}}}{\gamma_{\mathrm{r}}} \overline{C_{\mathrm{r}}}=0 \quad 0 \leq X \leq X_{1} \\
& \frac{\mathrm{d}^{2} \overline{C_{\mathrm{D}}}}{\mathrm{d} X^{2}}-P_{\mathrm{D}} \frac{\mathrm{d} \overline{C_{\mathrm{D}}}}{\mathrm{d} X}-\left(p+K_{\mathrm{D}}\right) \frac{P_{\mathrm{D}}}{\gamma_{\mathrm{D}}} \overline{C_{\mathrm{D}}}+K_{\mathrm{D}} \frac{P_{\mathrm{D}}}{\gamma_{\mathrm{D}}} \overline{C_{\mathrm{Dm}}}=0 \quad X_{1} \leq X \leq X_{2} \\
& \frac{\mathrm{d}^{2} \overline{C_{\mathrm{a}}}}{\mathrm{d} X^{2}}-P_{\mathrm{a}} \frac{\mathrm{d} \overline{C_{\mathrm{a}}}}{\mathrm{d} X}-\frac{p P_{\mathrm{a}}}{\gamma_{\mathrm{a}}} \overline{C_{\mathrm{a}}}=0 \quad X \geq X_{2}
\end{aligned}
$$

for the membrane

$$
\frac{\mathrm{d}^{2} \overline{C_{\mathrm{m}}}}{\mathrm{d} Y^{2}}-P_{\mathrm{m}} p \overline{C_{\mathrm{m}}}=0 \quad 2 \leq Y \leq 2+2 \Delta
$$


For the acceptor line

$\frac{\mathrm{d}^{2} \bar{C}_{\mathrm{f}}^{*}}{\mathrm{~d} X^{2}}-P_{\mathrm{f}}^{*} \frac{\mathrm{d} \bar{C}_{\mathrm{f}}^{*}}{\mathrm{~d} X}-\frac{p P_{\mathrm{f}}^{*}}{\gamma_{\mathrm{f}}^{*}} \overline{C_{\mathrm{f}}^{*}}=0 \quad X \leq X_{1}$

$\frac{\mathrm{d}^{2} \overline{C_{\mathrm{A}}}}{\mathrm{d} X^{2}}-P_{\mathrm{A}} \frac{\mathrm{d} \bar{C}_{\mathrm{A}}}{\mathrm{d} X}-\left(p+K_{\mathrm{A}}\right) \frac{P_{\mathrm{A}}}{\gamma_{\mathrm{A}}} \overline{C_{\mathrm{A}}}+K_{\mathrm{A}} \frac{P_{\mathrm{A}}}{\gamma_{\mathrm{A}}} \bar{C}_{\mathrm{Am}}=0 \quad X_{1} \leq X \leq X_{2}$

$\frac{\mathrm{d}^{2} \overline{C_{\mathrm{a}}^{*}}}{\mathrm{~d} X^{2}}-P_{\mathrm{a}}^{*} \frac{\mathrm{d} \bar{C}_{\mathrm{a}}^{*}}{\mathrm{~d} X}-\frac{p P_{\mathrm{a}}^{*}}{\gamma_{\mathrm{a}}^{*}} \overline{C_{\mathrm{a}}^{*}}=0 \quad X \geq X_{2}$

The corresponding boundary conditions can be obtained from those of Eqns 3-11 by simply replacing the concentrations with their Laplace transforms

The Laplace domain solutions of Eqns A1-A9 are the following

$\overline{C_{\mathrm{f}}}=A_{1} \exp \left[P_{\mathrm{f}}\left(05+q_{\mathrm{f}}\right)\left(X-X_{\mathrm{e}}\right)\right]$

$\bar{C}_{1}=A_{2} \exp \left[P_{1}\left(05+q_{1}\right) X\right]+A_{3} \exp \left[P_{1}\left(05-q_{1}\right) X\right]+1 / p$

$\overline{C_{\mathrm{r}}}=A_{4} \exp \left[P_{\mathrm{r}}\left(05+q_{\mathrm{r}}\right) X\right]+A_{5} \exp \left[P_{\mathrm{r}}\left(05-q_{\mathrm{r}}\right) X\right]$

$\overline{C_{\mathrm{D}}}=\sum_{t=1}^{t=4} r_{t} \exp \left[z_{t}\left(X-X_{1}\right)\right]$

$\widetilde{C_{\mathrm{a}}}=A_{6} \exp \left[P_{\mathrm{a}}\left(05-q_{\mathrm{a}}\right)\left(X-X_{2}\right)\right]$

$\overline{C_{\mathrm{f}}^{*}}=B_{1} \exp \left[P_{\mathrm{f}}^{*}\left(05+q_{\mathrm{f}}^{*}\right) X\right]$

$\widetilde{C_{\mathrm{A}}}=\sum_{i=1}^{\imath=4} \alpha_{i} r_{l} \exp \left[z_{t}\left(X-X_{1}\right)\right]$

$\bar{C}_{\mathrm{a}}^{*}=B_{2} \exp \left[P_{\mathrm{a}}^{*}\left(05-q_{\mathrm{a}}^{*}\right)\left(X-X_{2}\right)\right]$

where

$q_{j}=\left(\frac{p}{\gamma_{j} P_{j}}+025\right)^{1 / 2}$

The coefficients $A_{1}-A_{6}, B 1, B 2$ and $r_{1}$ are the unknown integrational constants which can be obtained from the boundary conditions of Eqns A1-A5 and A7-A9 The coefficients $\alpha_{i}$ can be determıned from solution of Eqn A6 [21]

$\alpha_{\imath}=-\frac{z_{\imath}^{2}-P_{\mathrm{D}} z_{\imath}-\left[p+K_{\mathrm{D}}\left(1-f_{\mathrm{D}}\right)\right] \frac{P_{\mathrm{D}}}{\gamma_{\mathrm{D}}}}{f_{\mathrm{A}} K_{\mathrm{D}} \frac{P_{\mathrm{D}}}{\gamma_{\mathrm{D}}}}$ 
where $z_{t}$ are the roots of the following biquadratic equation [21]

$$
\begin{aligned}
z^{4} & -\left(P_{\mathrm{D}}+P_{\mathrm{A}}\right) z^{3}+\left(P_{\mathrm{D}} P_{\mathrm{A}}-\left[p+K_{\mathrm{D}}\left(1-f_{\mathrm{D}}\right)\right] \frac{P_{\mathrm{D}}}{\gamma_{\mathrm{D}}}-\left[p+K_{\mathrm{A}}\left(1-g_{\mathrm{A}}\right)\right] \frac{P_{\mathrm{A}}}{\gamma_{\mathrm{A}}}\right) z^{2} \\
+ & P_{\mathrm{D}} P_{\mathrm{A}}\left(\frac{p+K_{\mathrm{D}}\left(1-f_{\mathrm{D}}\right)}{\gamma_{\mathrm{D}}}+\frac{p+K_{\mathrm{A}}\left(1-g_{\mathrm{A}}\right)}{\gamma_{\mathrm{A}}}\right) z \\
+ & \frac{P_{\mathrm{D}}}{\gamma_{\mathrm{D}}} \frac{P_{\mathrm{A}}}{\gamma_{\mathrm{A}}}\left(\left[p+K_{\mathrm{D}}\left(1-f_{\mathrm{D}}\right)\right]\left[p+K_{\mathrm{A}}\left(1-g_{\mathrm{A}}\right)\right]-K_{\mathrm{D}} K_{\mathrm{A}} f_{\mathrm{A}} g_{\mathrm{D}}\right)=0
\end{aligned}
$$

In the general case when the overall mass-transfer process in the membrane separation module is governed by the transfer both in the channels and in the membrane, the coefficients $f_{\mathrm{D}}, f_{\mathrm{A}}, g_{\mathrm{D}}$ and $g_{\mathrm{A}}$ are defined as follows [21]

$f_{\mathrm{D}}=\frac{H_{\mathrm{D}}}{F_{\mathrm{D}} Q}\left\{\left(q_{\mathrm{m}}+H_{\mathrm{A}} / F_{\mathrm{A}}\right) \exp \left(2 q_{\mathrm{m}} \Delta\right)+\left(q_{\mathrm{m}}-H_{\mathrm{A}} / F_{\mathrm{A}}\right) \exp \left(-2 q_{\mathrm{m}} \Delta\right)\right\}$

$f_{\mathrm{A}}=\left(H_{\mathrm{A}} / F_{\mathrm{D}} Q\right) 2 q_{\mathrm{m}}$

$g_{\mathrm{D}}=\left(H_{\mathrm{D}} / F_{\mathrm{A}} Q\right) 2 q_{\mathrm{m}}$

$g_{\mathrm{A}}=\left(H_{\mathrm{A}} / F_{\mathrm{A}} Q\right)\left[\left(q_{\mathrm{m}}+H_{\mathrm{D}} / F_{\mathrm{D}}\right) \exp \left(2 q_{\mathrm{m}} \Delta\right)+\left(q_{\mathrm{m}}-H_{\mathrm{D}} / F_{\mathrm{D}}\right) \exp \left(-2 q_{\mathrm{m}} \Delta\right)\right]$

where

$Q=\left(q_{\mathrm{m}}+H_{\mathrm{D}} / F_{\mathrm{D}}\right)\left(q_{\mathrm{m}}+H_{\mathrm{A}} / F_{\mathrm{A}}\right) \exp \left(2 q_{\mathrm{m}} \Delta\right)-\left(q_{\mathrm{m}}-H_{\mathrm{D}} / F_{\mathrm{D}}\right)\left(q_{\mathrm{m}}-H_{\mathrm{A}} / F_{\mathrm{A}}\right) \exp \left(-2 q_{\mathrm{m}} \Delta\right)$

$q_{\mathrm{m}}=\left(p P_{\mathrm{m}}\right)^{1 / 2}$

When the overall mass transfer is controlled only by the transfer in the channels of the membrane separation module, e $g$, the resistance of the membrane is negligible because $\Delta \rightarrow 0$, the expressions for $f_{\mathrm{D}}, f_{\mathrm{A}}, g_{\mathrm{D}}$ and $g_{\mathrm{A}}$ can be considerably simplified

$f_{\mathrm{D}}=\left(1+\frac{F_{\mathrm{D}}}{F_{\mathrm{A}}} \frac{K_{\mathrm{A}}}{k_{\mathrm{D}}}\right)^{-1}$

$f_{\mathrm{A}}=\left(\frac{F_{\mathrm{D}}}{F_{\mathrm{A}}}+\frac{k_{\mathrm{D}}}{k_{\mathrm{A}}}\right)^{-1}$

$g_{\mathrm{D}}=\left(\frac{F_{\mathrm{A}}}{F_{\mathrm{D}}}+\frac{k_{\mathrm{A}}}{k_{\mathrm{D}}}\right)^{-1}$

$g_{\mathrm{A}}=\left(1+\frac{F_{\mathrm{A}}}{F_{\mathrm{D}}} \frac{k_{\mathrm{D}}}{k_{\mathrm{A}}}\right)^{-1}$

Another extreme case is when the resistance of the membrane is much higher than that of the channels of the membrane separation module It can be assumed that the mass-transfer coefficients of both channels are infınitely hıgh, $1 \mathrm{e}, k_{\mathrm{D}} \rightarrow \infty$ and $k_{\mathrm{A}} \rightarrow \infty$ The following relationships necessary for the solution of Eqn A20 will hold

$$
\begin{aligned}
& K_{\mathrm{D}} f_{\mathrm{A}}=F_{\mathrm{A}} q_{\mathrm{m}} /\left[2 P_{\mathrm{m}} \sinh \left(2 q_{\mathrm{m}} \Delta\right)\right] \\
& K_{\mathrm{D}}\left(1-f_{\mathrm{D}}\right)=F_{\mathrm{D}} q_{\mathrm{m}} /\left[2 P_{\mathrm{m}} \tanh \left(2 q_{\mathrm{m}} \Delta\right)\right] \\
& K_{\mathrm{A}} g_{\mathrm{D}}=\left(a_{\mathrm{D}} / a_{\mathrm{A}}\right) F_{\mathrm{D}} q_{\mathrm{m}} /\left[2 P_{\mathrm{m}} \sinh \left(2 q_{\mathrm{m}} \Delta\right)\right] \\
& K_{\mathrm{A}}\left(1-g_{\mathrm{A}}\right)=\left(a_{\mathrm{D}} / a_{\mathrm{A}}\right) F_{\mathrm{A}} q_{\mathrm{m}} /\left[2 P_{\mathrm{m}} \tanh \left(2 q_{\mathrm{m}} \Delta\right)\right]
\end{aligned}
$$


The Laplace transforms of the concentration profiles in the flow sections situated upstream (1e , reactor) and downstream ( $1 \mathrm{e}$, after-section of the donor line) of the donor channel and downstream of the acceptor channel ( $\mathrm{e}$, after-section of the acceptor line) are the following

$$
\begin{aligned}
\overline{C_{\mathrm{r}}}= & \frac{1}{2 q_{\mathrm{r}}}\left\{\left[\sum_{t=1}^{t=4} r_{t}\left(05+q_{\mathrm{r}}-z_{\imath} / P_{\mathrm{D}}\right)\right] \exp \left[P_{\mathrm{r}}\left(05-q_{\mathrm{r}}\right)\left(X-X_{1}\right)\right]\right. \\
& \left.-\left[\sum_{t=1}^{t=4} r_{l}\left(05-q_{\mathrm{r}}-z_{\imath} / P_{\mathrm{D}}\right)\right] \exp \left[P_{\mathrm{r}}\left(05+q_{\mathrm{r}}\right)\left(X-X_{1}\right)\right]\right\} \quad 0 \leq X \leq X_{1}
\end{aligned}
$$

$\overline{C_{\mathrm{a}}}=\left\{\sum_{t=1}^{t=4} r_{t} \exp \left[z_{l}\left(X_{2}-X_{1}\right)\right]\right\} \exp \left[P_{\mathrm{a}}\left(05-q_{\mathrm{a}}\right)\left(X-X_{2}\right)\right] \quad X \geq X_{2}$

$\bar{C}_{\mathrm{a}}^{*}=\left\{\sum_{t=1}^{t=4} \alpha_{l} r_{t} \exp \left[z_{t}\left(X_{2}-X_{1}\right)\right]\right\} \exp \left[P_{\mathrm{a}}^{*}\left(05-q_{\mathrm{a}}^{*}\right)\left(X-X_{2}\right)\right] \quad X \geq X_{2}$

where

$$
\begin{aligned}
r_{1}= & h-r_{2} h_{1}^{1}-r_{3} h_{2}^{1}-r_{4} h_{3}^{1} \\
r_{2}= & \frac{h+r_{3}\left(h_{2}^{2}-h_{2}^{1}\right)+r_{4}\left(h_{3}^{2} h_{3}^{1}\right)}{h_{1}^{1}-h_{1}^{2}} \\
r_{3}= & \frac{h\left(h_{1}^{2}-h_{1}^{4}\right)+r_{4}\left[\left(h_{1}^{2}-h_{1}^{1}\right)\left(h_{3}^{4}-h_{3}^{1}\right)-\left(h_{1}^{4}-h_{1}^{1}\right)\left(h_{3}^{2}-h_{3}^{1}\right)\right]}{\left(h_{1}^{4}-h_{1}^{1}\right)\left(h_{2}^{2}-h_{2}^{1}\right)-\left(h_{1}^{2}-h_{1}^{1}\right)\left(h_{2}^{4}-h_{2}^{1}\right)} \\
r_{4}= & {\left[h \left(\left(h_{1}^{2}-h_{1}^{4}\right)\left[\left(h_{2}^{3}-h_{2}^{1}\right)\left(h_{1}^{2}-h_{1}^{1}\right)-\left(h_{1}^{3}-h_{1}^{1}\right)\left(h_{2}^{2}-h_{2}^{1}\right)\right]\right.\right.} \\
& \left.\left.-\left(h_{1}^{2}-h_{1}^{3}\right)\left[\left(h_{1}^{2}-h_{1}^{1}\right)\left(h_{2}^{4}-h_{1}^{2}\right)-\left(h_{2}^{2}-h_{2}^{1}\right)\left(h_{1}^{4}-h_{1}^{1}\right)\right]\right]\right] \\
& \times\left[\left(\left(h_{3}^{3}-h_{3}^{1}\right)\left(h_{1}^{2}-h_{1}^{1}\right)-\left(h_{3}^{2}-h_{3}^{1}\right)\left(h_{1}^{3}-h_{1}^{1}\right)\right]\left[\left(h_{1}^{2}-h_{1}^{1}\right)\left(h_{2}^{4}-h_{2}^{1}\right)-\left(h_{2}^{2}-h_{2}^{1}\right)\left(h_{1}^{4}-h_{1}^{1}\right)\right]\right. \\
& \left.-\left[\left(h_{1}^{2}-h_{1}^{1}\right)\left(h_{3}^{4}-h_{3}^{1}\right)-\left(h_{3}^{2}-h_{3}^{1}\right)\left(h_{1}^{4}-h_{1}^{1}\right)\right]\left[\left(h_{1}^{2}-h_{1}^{1}\right)\left(h_{2}^{3}-h_{2}^{1}\right)-\left(h_{2}^{2}-h_{2}^{1}\right)\left(h_{1}^{3}-h_{1}^{1}\right)\right]\right] \\
h=2 & q_{\mathrm{r}} M_{3} \exp \left[P_{\mathrm{r}}\left(05+q_{\mathrm{r}}\right) X_{1}\right] / S_{1} \\
h_{j}^{1}= & S_{j+1} / S_{1} \\
h_{J}^{2}= & {\left[\left(05-q_{\mathrm{a}}-z_{j+1} / P_{\mathrm{D}}\right) /\left(05-q_{\mathrm{a}}-z_{1} / P_{\mathrm{D}}\right)\right] \exp \left[\left(z_{j+1}-z_{1}\right)\left(X_{2}-X_{1}\right)\right] } \\
h_{j}^{3}= & {\left[\alpha_{j+1}\left(05+q_{\mathrm{f}}^{*}-z_{j+1} / P_{\mathrm{A}}\right)\right] /\left[\alpha_{1}\left(05+q_{\mathrm{f}}^{*}-z_{1} / P_{\mathrm{A}}\right)\right] } \\
h_{j}^{4}= & {\left[\alpha_{j+1}\left(05-q_{\mathrm{a}}^{*}-z_{j+1} / P_{\mathrm{A}}\right)\right] /\left[\alpha_{1}\left(05-q_{\mathrm{a}}^{*}-z_{1} / P_{\mathrm{A}}\right)\right] \exp \left[\left(z_{j+1}-z_{1}\right)\left(X_{2}-X_{1}\right)\right] }
\end{aligned}
$$

where $j=1,2,3$,

$S_{j}=2 q_{\mathrm{r}} M_{1}+\left[M_{2} \exp \left[2 P_{\mathrm{r}} q_{\mathrm{r}} X_{1}\right]-M_{1}\right]\left(05+q_{\mathrm{r}}-z_{j} / P_{\mathrm{D}}\right)$

where $y=1,2,3,4$,

$$
\begin{aligned}
M_{1}= & \left(q_{\mathrm{r}}-q_{1}\right)\left(q_{\mathrm{f}}+q_{1}\right) \exp \left[-2 P_{1} q_{1} X_{\mathrm{e}}\right]-\left(q_{\mathrm{r}}+q_{\mathrm{l}}\right)\left(q_{\mathrm{f}}-q_{1}\right) \\
M_{2}= & \left(q_{\mathrm{r}}-q_{1}\right)\left(q_{\mathrm{f}}-q_{1}\right)-\left(q_{\mathrm{f}}+q_{\mathrm{t}}\right)\left(q_{\mathrm{r}}+q_{1}\right) \exp \left[-2 P_{1} q_{1} X_{\mathrm{e}}\right] \\
M_{3}= & {\left[\left(05-q_{1}\right)\left(q_{\mathrm{f}}-q_{1}\right)+2 q_{1}\left(05+q_{\mathrm{f}}\right) \exp \left[-P_{\mathrm{l}}\left(05+q_{\mathrm{l}}\right) X_{\mathrm{e}}\right]\right.} \\
& \left.-\left(05+q_{\mathrm{l}}\right)\left(q_{\mathrm{f}}+q_{\mathrm{l}}\right) \exp \left[-2 P_{\mathrm{l}} q_{1} X_{\mathrm{e}}\right]\right] / p
\end{aligned}
$$


If the membrane is impermeable to the analyte, the dispersion process in the donor channel will be described by Eqn A24 instead of Eqn A13

$\overline{C_{\mathrm{D}}}=A_{7} \exp \left[P_{\mathrm{D}}\left(05+q_{\mathrm{D}}\right)\left(X-X_{1}\right)\right]+A_{8} \exp \left[P_{\mathrm{D}}\left(05-q_{\mathrm{D}}\right)\left(X-X_{1}\right)\right]$

The Laplace transform of the concentration profile monitored in the donor line downstream of the donor channel (i e, in the after-section) will be given by Eqn A14, where

$$
\begin{aligned}
A_{6}= & \frac{1}{p}\left\{4 q_{\mathrm{r}} q_{\mathrm{D}} \exp \left[P_{\mathrm{r}}\left(05-q_{\mathrm{r}}\right) X_{1}+P_{\mathrm{D}}\left(05-q_{\mathrm{D}}\right)\left(X_{2}-X_{1}\right)\right]\right. \\
& \left.\times\left\{\left(05+q_{1}\right)\left(q_{\mathrm{f}}+q_{\mathrm{l}}\right)-\left(05-q_{1}\right)\left(q_{\mathrm{f}}-q_{1}\right) \exp \left[2 P_{1} q_{1} X_{\mathrm{e}}\right]-2 q_{1}\left(05+q_{\mathrm{f}}\right) \exp \left[-P_{1}\left(05-q_{1}\right) X_{\mathrm{e}}\right]\right\}\right\} \\
& \times\left\{\left\{\left(q_{\mathrm{a}}+q_{\mathrm{D}}\right)\left(q_{\mathrm{r}}+q_{\mathrm{D}}\right)-\left(q_{\mathrm{a}}-q_{\mathrm{D}}\right)\left(q_{\mathrm{r}}-q_{\mathrm{D}}\right) \exp \left[-2 P_{\mathrm{D}} q_{\mathrm{D}}\left(X_{2}-X_{1}\right)\right]\right\}\right. \\
& \times\left\{\left(q_{\mathrm{r}}+q_{1}\right)\left(q_{\mathrm{f}}+q_{1}\right)-\left(q_{\mathrm{f}}-q_{1}\right)\left(q_{\mathrm{r}}-q_{\mathrm{l}}\right) \exp \left[-2 P_{1} q_{1} X_{\mathrm{e}}\right]\right\}-\left\{\left(q_{\mathrm{r}}-q_{1}\right)\left(q_{\mathrm{f}}+q_{1}\right)-\left(q_{\mathrm{r}}+q_{1}\right)\right. \\
& \left.\times\left(q_{\mathrm{f}}-q_{1}\right) \exp \left[-2 P_{1} q_{1} X_{\mathrm{e}}\right]\right\} \\
& \left.\times\left\{\left(q_{\mathrm{a}}+q_{\mathrm{D}}\right)\left(q_{\mathrm{r}}-q_{\mathrm{D}}\right)-\left(q_{\mathrm{a}}-q_{\mathrm{D}}\right)\left(q_{\mathrm{r}}+q_{\mathrm{D}}\right) \exp \left[-2 P_{\mathrm{D}} q_{\mathrm{D}}\left(X_{2}-X_{1}\right)\right]\right\} \exp \left[-2 P_{\mathrm{r}} q_{\mathrm{r}} X_{1}\right]\right\}^{-1}
\end{aligned}
$$

\section{APPENDIX B}

Implicut finte-difference equations for the membrane separation module

The $\theta, X$ and $Y$ regions of interest were divided into $K, N$ and $M$ sub-intervals, respectively, so that it can be written

$$
\begin{array}{lll}
\theta=k \Delta \theta & (k=0,1,2, & , K) \\
X=\imath \Delta X & (\iota=0,1,2, & , N) \\
Y=\jmath \Delta Y & (J=0,1,2, & , M)
\end{array}
$$

\section{X-ımplıcıt equatıons}

$$
\begin{aligned}
& -\frac{\gamma_{\mathrm{D}} \Delta \theta}{4 \Delta X}\left(1+\frac{1}{P_{\mathrm{D}} \Delta X}\right) C_{\mathrm{D}_{\imath-1} k+0.5}+\left[1+\frac{\Delta \theta \gamma_{\mathrm{D}}}{(\Delta X)^{2} P_{\mathrm{D}}}\right] C_{\mathrm{D}_{\imath k+05}}+\frac{\gamma_{\mathrm{D}} \Delta \theta}{4 \Delta X}\left(1-\frac{2}{P_{\mathrm{D}} \Delta X}\right) C_{\mathrm{D}_{t+1} k+0.5} \\
& =\left(1-\frac{K_{\mathrm{D}} \Delta \theta}{2}\right) C_{\mathrm{D}_{1 k}}+\frac{K_{\mathrm{D}} \Delta \theta}{2 F_{\mathrm{D}}} C_{\mathrm{m}_{i 0 k}} \\
& -\frac{\gamma_{\mathrm{A}} \Delta \theta}{4 \Delta X}\left(1+\frac{2}{P_{\mathrm{A}} \Delta X}\right) C_{\mathrm{A}_{t-1 k+05}}+\left[1+\frac{\Delta \theta \gamma_{\mathrm{A}}}{(\Delta X)^{2} P_{\mathrm{A}}}\right] C_{\mathrm{A}_{t k+0 s}}+\frac{\gamma_{\mathrm{A}} \Delta \theta}{4 \Delta X}\left(1-\frac{2}{P_{\mathrm{A}} \Delta X}\right) C_{\mathrm{A}_{t+1 k+0}} \\
& =\left(1-\frac{K_{\mathrm{A}} \Delta \theta}{2}\right) C_{\mathrm{A}_{i k}}+\frac{K_{\mathrm{A}} \Delta \theta}{2 F_{\mathrm{A}}} C_{\mathrm{m}_{i, k}} \\
& C_{\mathrm{m}_{\imath+k+0 s}}=\frac{1}{1+H_{\mathrm{D}} \Delta Y / F_{\mathrm{D}}}\left(C_{\mathrm{m}_{\imath \downarrow k+0 s}}+H_{\mathrm{D}} \Delta Y C_{\mathrm{D}_{\imath k+0 S}}\right) \text { for } \mathrm{J}=0 \\
& C_{\mathrm{m}_{\imath, k+05}}=\left(1-\frac{\Delta \theta}{(\Delta Y)^{2} P_{\mathrm{m}}}\right) C_{\mathrm{m}_{\imath \jmath k}}+\frac{\Delta \theta}{2(\Delta Y)^{2} P_{\mathrm{m}}}\left(C_{\mathrm{m}_{\imath \jmath+1 k}}+C_{\mathrm{m}_{\imath \jmath-1 k}}\right) \text { for } 0<\jmath<M \\
& C_{\mathrm{m}_{\imath M k+0 s}}=\frac{1}{1+H_{\mathrm{A}} \Delta Y / F_{\mathrm{A}}}\left(C_{\mathrm{m}_{\imath M-1 k+0.5}}+H_{\mathrm{A}} \Delta Y C_{\mathrm{A}_{\imath k+0 s}}\right) \text { for } \jmath=M
\end{aligned}
$$


Y-implictt equations

$C_{\mathrm{D}_{\imath k+1}}=\frac{\gamma_{\mathrm{D}} \Delta \theta}{4 \Delta X}\left(1+\frac{2}{P_{\mathrm{D}} \Delta X}\right) C_{\mathrm{D}_{\imath-1} k+05}+\left[1-\frac{\Delta \theta \gamma_{\mathrm{D}}}{(\Delta X)^{2} P_{\mathrm{D}}}-\frac{K_{\mathrm{D}} \Delta \theta}{2}\right] C_{\mathrm{D}_{t k+0.5}}$

$-\frac{\gamma_{D} \Delta \theta}{4 \Delta X}\left(1-\frac{2}{P_{\mathrm{D}} \Delta X}\right) C_{\mathrm{D}_{\imath+1} k+0 s}+\frac{K_{\mathrm{D}} \Delta \theta}{2 F_{\mathrm{D}}} C_{m_{\imath 0 k+0.5}}$

$C_{\mathrm{A}_{t k+1}}=\frac{\gamma_{\mathrm{A}} \Delta \theta}{4 \Delta X}\left(1+\frac{2}{P_{\mathrm{A}} \Delta X}\right) C_{\mathrm{A}_{t-1} k+0.5}+\left[1-\frac{\Delta \theta \gamma_{\mathrm{A}}}{(\Delta X)^{2} P_{\mathrm{A}}}-\frac{K_{\mathrm{A}} \Delta \theta}{2}\right] C_{\mathrm{A}_{t k+0 . s}}$

$-\frac{\gamma_{\mathrm{A}} \Delta \theta}{4 \Delta X}\left(1-\frac{2}{P_{\mathrm{A}} \Delta X}\right) C_{\mathrm{A}_{i+1 k+05}}+\frac{K_{\mathrm{A}} \Delta \theta}{2 F_{\mathrm{A}}} C_{\mathrm{m}_{i, M k+05}}$

$\left(1+\frac{H_{\mathrm{D}} \Delta Y}{F_{\mathrm{D}}}\right) C_{\mathrm{m}_{\imath 0 k+1}}-C_{\mathrm{m}_{\imath 1 k+1}}=H_{\mathrm{D}} \Delta Y C_{\mathrm{D}_{\imath k+1}}$ for $\jmath=0$

$\frac{\Delta \theta}{2(\Delta Y)^{2} P_{\mathrm{m}}} C_{\mathrm{m}_{\imath, j-1} k+1}-\left[1+\frac{\Delta \theta}{(\Delta Y)^{2} P_{\mathrm{m}}}\right] C_{\mathrm{m}_{\ell, k+1}}+\frac{\Delta \theta}{2(\Delta Y)^{2} P_{\mathrm{m}}} C_{\mathrm{m}_{i j+1 k+1}}=-C_{\mathrm{m}_{\ell, k+05}}$ for $0<\jmath<M$

$-C_{\mathrm{m}_{\imath M-1 k+1}}+\left(1+\frac{H_{\mathrm{A}} \Delta Y}{F_{\mathrm{A}}}\right) C_{\mathrm{m}_{\imath} M k+1}=H_{\mathrm{A}} \Delta Y C_{\mathrm{A}_{t k+1}}$ for $J=M$

Both the sets of $X$-implicit and $Y$-implicit equations have a tridiagonal coefficient matrix and were solved in a straightforward way by the Gaussian elimination method [25]

APPENDIX C

Equations for calculating the steady-state membrane permeabilty

The concentrations at the outlets of the donor and the acceptor channels under steady-state conditions $(1 \mathrm{e}, \partial C / \partial \theta=0)$ can be calculated by the following equations [29]

$C_{\mathrm{D}}=\frac{\omega}{\omega-F_{\mathrm{D}} / F_{\mathrm{A}}}\left\{1-\frac{F_{\mathrm{D}}}{\omega F_{\mathrm{A}}} \exp \left[\beta\left(X_{2}-X_{1}\right)\right]\right\}$

$C_{\mathrm{A}}=\frac{\omega}{\omega F_{\mathrm{A}} / F_{\mathrm{D}}-1}\left\{1-\exp \left[\beta\left(X_{2}-X_{1}\right)\right]\right\}$

The coefficient $\beta$ is the only negative root of Eqn C3 and can be calculated analytically by Cardan's equation [30]

$z^{3}-\left(P_{\mathrm{D}}+P_{\mathrm{A}}\right) z^{2}+\left[P_{\mathrm{D}} P_{\mathrm{A}}-\Psi\left(\frac{v_{\mathrm{A}}}{v_{\mathrm{D}}} F_{\mathrm{D}} P_{\mathrm{D}}+F_{\mathrm{A}} P_{\mathrm{A}}\right)\right] z+\Psi P_{\mathrm{D}} P_{\mathrm{A}}\left(\frac{v_{\mathrm{A}}}{v_{\mathrm{D}}} F_{\mathrm{D}}+F_{\mathrm{A}}\right)=0$ 
where

$\Psi=\left[\frac{v_{\mathrm{A}}}{v_{\mathrm{D}}} \gamma_{\mathrm{D}}\left(\frac{a_{\mathrm{D}}}{a_{\mathrm{A}}} \frac{F_{\mathrm{A}}}{K_{\mathrm{A}}}+\frac{F_{\mathrm{D}}}{K_{\mathrm{D}}}+4 P_{\mathrm{m}} \Delta\right)\right]^{-1}$

Once determined, $\beta$ can be used for calculating the coefficient $\omega$ in Eqns $\mathrm{C} 1$ and $\mathrm{C} 2$

$\omega=\frac{v_{\mathrm{D}} \beta}{v_{\mathrm{A}} F_{\mathrm{A}} \Psi}\left(1-\frac{\beta}{P_{\mathrm{D}}}\right)+\frac{F_{\mathrm{D}}}{F_{\mathrm{A}}}$

\section{REFERENCES}

$1 \mathrm{~J}$ Ruzicka and E H Hansen, Flow Injection Analysis, Wiley, New York, 2nd edn , 1988

$2 \mathrm{M}$ Valcárcel and M D Luque de Castro, Flow-Injection Analysıs Principles and Applications, Horwood, Chichester, 1987

3 E H Hansen and J Ruzıcka, Anal Chım Acta, 87 (1976) 353

4 L Gorton and L Ogren, Anal Chım Acta, 130 (1981) 45

5 J F van Staden and A van Rensburg, Analyst, 115 (1990) 1049

6 B Bernhardsson, E Martıns and G Johansson, Anal Chım Acta, 167 (1985) 111

7 L Risinger, G Johansson and T Thorneman, Anal Chim Acta, 224 (1989) 13

8 I $C$ van Nugteren-Osinga, $M$ Bos and $W E$ van der Lınden, Anal Chım Acta, 214 (1988) 77

9 I C van Nugteren-Osınga, $\mathrm{PhD}$ Thesis, Twente University, Enschede, 1991

10 O Levenspiel and K.B Bischoff, Adv Chem Eng, 4 (1963) 95

11 C Y Wen and L T Fan, Models for Flow Systems and Chemical Reactors, Dekker, New York, 1968

12 W E van der Lınden, Anal Chum Acta, 151 (1983) 359

$13 \mathrm{~J} M$ Reijn, WE van der Linden and $H$ Poppe, Anal Chım Acta, 114 (1980) 105

$14 \mathrm{~J} M$ Reıjn, W E van der Linden and $H$ Poppe, Anal Chım Acta, 126 (1981) 1
15 S D Kolev and E Pungor, Anal Chem, 60 (1988) 1700

16 S D Kolev and E Pungor, Anal Chim Acta, 208 (1988) 117

17 S D Kolev and E Pungor, Anal Chim Acta, 208 (1988) 133

18 G Taylor, Proc R Soc London, Ser A, 219 (1953) 186

19 G Taylor, Proc R Soc London, Ser A, 225 (1954) 231

20 S D Kolev and W E van der Linden, Anal Chim Acta, 247 (1991) 51

21 S D Kolev and W E van der Linden, Anal Chim Acta, 257 (1992) 331

22 S D Kolev and E Pungor, Talanta, 34 (1987) 1009

23 S D Kolev and E Pungor, Anal Chım Acta, 194 (1987) 61

24 S D Kolev, G Nagy and E Pungor, Anal Chım Acta, 241 (1990) 43

25 B Carnahan, H A Luther and J O Wilkes, Applied Numerical Methods, Wiley, New York, 1969

26 J A. Nelder and R Mead, Comput J, 7 (1964) 308

27 E Th Van der Laan, Chem Eng Sc1, 7 (1958) 187

28 A M Suhotına (Ed), Handbook of Electrochemıstry, Khımıya, Lenıngrad, 1st edn , 1981

29 S D Kolev and W E van der Linden, Anal Chim Acta, 256 (1992) 301

30 G A. Korn and T M Korn, Mathematical Handbook, McGraw-Hill, New York, 1968 